Revista de Negócios_ISSN 1980.4431_vol. 18, n.4, p.33_54, 2013_DOI:10.7867/1980-

431.2013v18n4p33_54

\title{
Gestão orientada a processos de negócio: oportunidades para melhoria da execução estratégica em uma refinaria de petróleo
}

\section{Management oriented business processes: opportunities for improving strategic execution in an oil refinery}

Alberto Pavlick Caetani

UFRGS Universidade Federal do Rio Grande do Sul - Brasil

cae004@gmail.com

Raquel Janissek-Muniz

UFRGS Universidade Federal do Rio Grande do Sul - Brasil

rjmuniz@ufrgs.br

Marinês Steffanello

UFRGS Universidade Federal do Rio Grande do Sul - Brasil

stefanello@ufrgs.br

Everton da Silveira Farias

UFRGS Universidade Federal do Rio Grande do Sul - Brasil

evertonfarias@ufrgs.br

Recebido em 27 de setembro de 2011. Alterado em 2 de março de 2013. Aprovado em 26 de março de 2013.

Editor Responsável: Edson Roberto Scharf, Dr.

Processo de avaliação por double blind review

\section{Resumo}

Embora parte significativa da produção acadêmica direcione-se para o processo de formulação das estratégias, a implementação tem-se revelado um desafio maior para as organizações, estimando-se que grande parte dos casos de fracassos na estratégia seja decorrência da má execução. Este trabalho foca na superação dos obstáculos enfrentados para implementação das ações estratégicas sob a perspectiva da gestão dos processos internos, buscando entender como a gestão orientada a processos de negócio poderia ajudar as empresas a melhorar seu desempenho e aumentar sua capacidade de execução estratégica. O Estudo de Caso realizado junto a uma indústria do ramo de petróleo, levantou informações sobre os processos organizacionais através de pesquisa documental e da aplicação de questionários junto aos principais gestores e pessoas-chave na empresa. Para apoiar a análise dos dados foram estabelecidas relações entre os conceitos-chave do estudo e as variáveis avaliadas nos quatro instrumentos de pesquisa, buscando-se efetivar a triangulação entre as percepções dos diferentes sujeitos consultados e os dados recolhidos na pesquisa documental. Os resultados apurados demonstraram que os principais obstáculos enfrentados pela empresa para 
Gestão orientada a processos de negócio: oportunidades para melhoria da execução estratégica em uma refinaria de petróleo

executar as ações propostas em seu Planejamento Estratégico poderiam ser, pelo menos em parte, superadas através da implementação de práticas de gestão orientadas a processos. Visando apoiar os esforços para aumentar a capacidade de execução estratégica foram identificadas ações de melhoria para viabilizar o aumento do grau de maturidade da empresa em relação à gestão orientada a processos de negócio.

Palavras-chave: gestão orientada, processos de negócio, desempenho, indústria de petróleo.

\begin{abstract}
Although significant part of academic address yourself to the process of formulating strategies, implementation has proved a major challenge for organizations, it is estimated that most cases of failures in strategy is due to poor execution. This paper focuses on overcoming the obstacles faced in the implementation of strategic actions from the perspective of the management of internal processes, seeking to understand how the management-oriented business processes could help firms improve their performance and increase their ability to execute strategic. The case study conducted with a field of oil industry, raised about organizational processes through documentary research and questionnaires with key managers and key people in the company. To support the analysis of the data relations were established between the key concepts of the study and the variables evaluated in the four research instruments, seeking to carry out the triangulation between the perceptions of different subjects consulted and the data collected in the research document. The results obtained showed that the main obstacles faced by the company to perform the actions proposed in its Strategic Plan could be at least partly overcome through the implementation of management practices oriented processes. To support efforts to increase the ability to execute strategic actions for improvement have been identified to facilitate the increased maturity of the company in relation to management-oriented business processes. Keywords: oriented management, business processes, performance, oil industry.
\end{abstract}

\section{Introdução}

A dinâmica da execução das ações estratégicas dentro do processo de Administração Estratégica é um tema que tem suscitado discussões no meio acadêmico e empresarial. Estudos indicam que apenas uma pequena parcela das ações estratégicas planejadas é implementada com êxito pelas organizações, estimando- se taxas de falhas na implementação entre $70 \%$ e $90 \%$, de tal forma que muitos executivos sustentam que a capacidade de executar a estratégia pode ser mais importante que a própria estratégia em si (KAPLAN; NORTON, 2001). Além de fatores externos e da dinamicidade própria do ambiente competitivo, existem outros obstáculos, de caráter interno, que inibem a capacidade de execução estratégica das empresas (HREBINIAK, 2006; VRAKKING, 1995). A compreensão desses obstáculos é fundamental para viabilizar sua superação em um ambiente instável e competitivo, vinculando-se às questões relativas à gestão dos processos de negócio na medida em que os resultados das organizações são determinados por seus processos.

Mais que tecnologia, a implementação de estratégias competitivas exige uma transformação das organizações. A empresa precisa cada vez mais voltar-se para seus clientes, operando e acompanhando suas operações a partir de uma visão orientada aos processos de negócio que agregam valor para o cliente. Conforme Armistead, Pritchard e Machin (1999, p. 105) a resposta que os gestores dão para a questão "O que a gestão de processos de negócio significa para sua organização?" varia de acordo com o modo (e resultados) da inserção da gestão dos processos nas respectivas organizações, mas é inegável a influência que a mesma exerce sobre a efetividade organizacional, ou seja, no atendimento das expectativas de desempenho das diversas partes interessadas.

De acordo com Rummler e Brache (1995), a capacidade de adaptação ao ambiente competitivo é essencial para a sobrevivência das organizações, sendo o modelo de gestão o fator-chave que viabiliza adaptações mais rápidas e efetivas. Dessa forma, a eficácia da implementação das estratégias passa, em grande parte das empresas, pelo desafio da mudança organizacional e da revisão de seu modelo de gestão (MOTTA, 1995). No 
Alberto Pavlick Caetani

Marinês Steffanello

entanto, existe um amplo entendimento (HECKSCHER, 2007; HARMON, 2004; FISCHER, 2004; ROSEMANN; DEBRUIN; HUEFFNER, 2004; MCCORMACK; JOHNSON, 2001) no sentido de que a implementação de práticas de gestão orientadas a processos tem um caráter evolutivo, acompanhando a maturidade da organização em relação aos temas processo e estratégia. Neste sentido entende-se a Gestão Orientada a Processos de Negócio como um modelo de gestão que viabiliza a convergência de estratégias, recursos e competências dentro das empresas, em contraposição aos modelos empresariais cuja visão vertical resulta em ações fragmentadas em relação aos fluxos dentro da Cadeia de Valor.

Embora reconhecendo que o sucesso (ou fracasso) das empresas está relacionado a um complexo conjunto de variáveis internas e externas à organização, este trabalho concentra-se na importância da gestão dos processos internos como elemento de diferenciação das empresas, buscando contribuir para o entendimento do papel estratégico da gestão dos processos, ao mesmo tempo em que analisa e fornece elementos objetivos para a mudança organizacional de uma refinaria de petróleo.

Com o objetivo de identificar oportunidades para melhoria da capacidade de execução estratégica a partir de mudanças organizacionais decorrentes da aplicação de práticas de gestão orientadas a processos, realizou-se um estudo de caso único junto à indústria do ramo de petróleo. Na seção 2 são discutidos os conceitos de desempenho organizacional, gestão orientada a processos e maturidade em gestão de processos; na seção 3 apresenta-se o procedimento metodológico adotado para a elaboração do Estudo de Caso, enquanto que na seção 4 apresentam-se os resultados do trabalho, as análises realizadas e as ações propostas; finalmente, na seção 5 são apresentadas as considerações finais, limitações da pes-
Raquel Janissek-Muniz

Everton da Silveira Farias

quisa e sugestões para estudos complementares.

\section{Execução Estratégica e Gestão de Processos}

A implementação, ou execução, da estratégia implica em traduzir as estratégias em resultados, ou seja, na efetiva aplicação das decisões estratégicas sobre fatores organizacionais, tais como estrutura, coordenação, compartilhamento de informações, incentivos e controles, dentro de um contexto organizacional que inclui dimensões referentes à gestão da mudança, cultura organizacional, estrutura de poder e liderança.

O desafio da execução estratégica é, fundamentalmente, o desafio natural de gerenciar mudanças nas organizações, ampliado ainda mais pela complexidade decorrente da multiplicidade de fatores interdependentes envolvidos no processo de gestão estratégica em um ambiente econômico dinâmico e imprevisível. Diversos autores (KAPLAN; NORTON, 1996; EISENSTAT, 2000; BEER; MANKINS; STEELE, 2005; HREBINAK, 2006; NEILSON; MARTIN; POWERS, 2008; GODED; DURANCE, 2011) têm desenvolvido estudos referentes aos problemas e dificuldades que afetam a implementação da estratégia nas empresas, relacionando-os, principalmente, ao comportamento corporativo vinculado à liderança, ao fluxo das informações e à coordenação interfuncional.

\subsection{Desempenho organizacional}

A medição do desempenho, enquanto fator de direcionamento do comportamento nas organizações, torna-se parte integrante do processo de gestão estratégica, influenciando diretamente a implementação da estratégia na medida em que pode ser utilizada tanto para dar foco nas atividades críticas, como para sinalizar aos gestores a necessidade de intervenção em função de deterioração do desempenho 
Gestão orientada a processos de negócio: oportunidades para melhoria da execução estratégica em uma refinaria de petróleo

dos negócios (NEELY et al., 1994). Conforme Adler (2009), a complexidade do ambiente competitivo reflete-se em múltiplas dimensões de desempenho, forçando as empresas, cada vez mais, a desenvolverem habilidades "ambidestras", ou seja, simultaneamente explorar as capacidades existentes e prospectar oportunidades de desenvolver novas capacidades. Neste sentido conhecer o desempenho atual da empresa torna-se essencial para o entendimento do nível de mobilização organizacional para as mudanças exigidas, ou seja, para identificar a existência do que Kotter (1997) designa como "senso de urgência grande o suficiente" capaz de mobilizar os recursos necessários para a transformação da organização.

Conforme Kaplan e Norton (2001, p. 3) "success comes from having strategy become everyone's everyday job", ou seja, é necessário traduzir a estratégia em termos mais operacionais, desdobrando-a em todos os níveis organizacionais e acompanhando o desempenho dos processos identificados como críticos, de modo a garantir o alinhamento das atividades para melhoria dos processos com as prioridades estratégicas. Embora as organizações execu-tem centenas de processos, cada qual agregando algum tipo de valor, Kaplan e Norton (2001) afirmam que a arte da estratégia é identificar e otimizar os poucos processos críticos que respondem pela proposição de valor ao cliente. Uma estratégia bem-sucedida e sustentável, portanto, consiste em assegurar o alinhamento entre as atividades internas $\mathrm{e}$ a geração de valor para o cliente. Para Godet (2000), a eficácia estratégica de uma organização depende não apenas do perfeito alinhamento das atividades com sua cadeia de valor, mas também da efetiva integração da estratégia à cultura e identidade de cada organização, ou seja, de sua apropriação por todos os atores envolvidos a partir de uma "mobilização da inteligência coletiva".

\subsection{Gestão Orientada a Processos}

$O$ funcionamento de uma organização depende das escolhas que a administração faz em relação aos objetivos da empresa, estrutura, distribuição de atividades, coordenação, comunicação e atribuição de responsabilidades e autoridade. $\mathrm{O}$ conjunto destas decisões normalmente permite que se identifique a empresa com uma das duas visões predominantes no contexto de gestão: visão funcional ou visão por processo. Estas decisões não apenas refletem o modo como os executivos enxergam a organização, mas também, de certa forma, aspectos da própria cultura organizacional.

Tradicionalmente, tendo por base os princípios da Administração Científica, as organizações adotavam modelos baseados na divisão de cada operação em tarefas básicas, unidades funcionais e seus mecanismos de coordenação. De acordo com Santos (2002), esse modelo de gestão, funcional, vertical e orientado pela responsabilidade, caracteriza-se pela descentralização de objetivos, pelo isolamento dos diversos setores da empresa ("cultura de silos") e por priorizar as relações explicitadas na estrutura organizacional. Entre os principais problemas decorrentes da visão funcional nas empresas, destacase a dificuldade de integração entre as diferentes funções e o estabelecimento de competição interna, com implicações negativas para o desempenho. pois geralmente a otimização isolada de funções acarreta perda de eficiência global e prejuízos para a empresa como um todo.

As limitações apresentadas pelos modelos de gestão tradicionais, baseados na especialização e na divisão funcional do trabalho, em relação à capacidade de adaptação às mudanças no ambiente e aos requisitos de integração e de coordenação das atividades, evidenciaram a necessidade das empresas em conceber, modelar e implementar processos de negócio de acordo com a proposição de valor estabelecida em sua estratégia. A partir das definições elaboradas por alguns dos 
principais autores da área, tais como Harrington (1993), Rummler e Brache (1995) e Hammer e Champy (1994), processo de negócio pode ser entendido como um conjunto de atividades, logicamente integradas, que utilizam recursos para produzir resultado (produto ou serviço) para um cliente, em conformidade com os objetivos da empresa e integrado a uma cadeia de agregação de valor. Mais recentemente, Heckscher (2007) discute a necessidade de expansão dos processos de negócio para além das fronteiras das organizações, integrando parceiros externos capazes de agregar conhecimento crítico para o negócio, constituindo ecossistemas produtivos ou, o que ele designa, corporações colaborativas ("collaborative enterprises"). Embora estejam presentes em todo tipo de empresa, os processos de negócio nem sempre estão "visíveis" para os integrantes, e mesmo gestores, o que acaba por afetar sua capacidade de atingir objetivos.

A partir da compreensão da importância da gestão dos processos para a melhoria do desempenho, foram desenvolvidas teorias organizacionais que consolidaram o conceito de orientação a processos, ou visão horizontal das organizações, cujas práticas revelaram-se mais adequadas para assegurar que a execução e monitoração das mudanças nos processos de negócio sejam realizadas de modo alinhado à estratégia das empresas (SANTOS, 2007). Empresas com visão horizontal são colaborativas, organizam-se em torno de processos multifuncionais (ao invés de tarefas ou funções isoladas) de modo que as informações sobre a execução das atividades possibilitem que as interdependências sejam compreendidas em suas relações de causa e efeito, consolidadas em indicadores de desempenho que reflitam os resultados dos processos de negócio e sirvam de insumo relevante para a tomada de decisão (RUMMLER; BRACHE, 1995). Ostroff (1999) destaca que as organizações horizontais priorizam a formação de equipes multidisciplinares, com indivíduos capazes de pensar de modo criativo e tomar decisões, utilizando recursos de tecnologia da informação tanto como fator de produtividade, como para suportar a integração com fornecedores e clientes, focadas na inovação, na melhoria contínua dos processos de negócio e no cumprimento da proposta de valor para os clientes. Mais do que grupos autônomos, estáveis e formalmente estruturados, os desafios de uma economia baseada no conhecimento exigem arranjos colaborativos mais flexíveis, fluidos, capazes de harmonizar diferentes habilidades e competências. Esta colaboração estendida é particularmente adequada para suportar processos de inovação, na medida em que potencializa a responsividade organizacional, capacidade de perceber e reagir aos estímulos do ambiente, assim como viabiliza novas formas de uso e combinação de conhecimentos complexos (HECKSCHER, 2007).

Conforme Hammer (2007), processos de negócio de alto desempenho são caracterizados pela existência de desenho (modelo de processo que define quais tarefas devem ser executadas, assim como quem, quando, onde e sob quais circunstâncias); métricas de desempenho (padrões utilizados para avaliação do desempenho do processo derivadas das necessidades dos clientes e dos objetivos estratégicos); executantes qualificados (as pessoas envolvidas na execução das atividades possuem, além da capacitação técnica, habilidades e comportamento adequados para o trabalho em equipe); proprietário (process-owner ou gestor com autoridade e responsabilidade pelo processo completo ao longo de toda a organização); infra-estrutura de suporte (sistema de informação integrado e um conjunto consistente de práticas de gestão de recursos humanos: carreira, capacitação e recompensa). 
Gestão orientada a processos de negócio: oportunidades para melhoria da execução estratégica em uma refinaria de petróleo

\subsection{Maturidade em Gestão de Processos}

O conceito de maturidade na gestão de processos teve início em 1979 com o modelo desenvolvido por Philip Crosby para descrever os cinco estágios envolvidos na evolução do gerenciamento da qualidade, sendo posteriormente adaptado pela SEI (Software Engineering Institute) em seu Capability Maturity Model (CMM) para avaliação dos processos de desenvolvimento de software (PAULK, 2009). Conforme Harmon (2004), organizações maduras buscam resultados através de processos executados de forma estruturada e sistemática, enquanto as imaturas, quando obtém resultados, os mesmos são decorrentes de esforços isolados, utilizando abordagens nãoestruturadas. A avaliação da situação atual em relação a parâmetros pré-definidos de orientação a processos de negócio, utilizando-se de um modelo de maturidade, é um importante instrumento de apoio aos gestores, pois, além de direcionar os esforços de mudança, também possibilita acompanhar e medir o progresso da organização em relação à implementação de práticas de gestão orientadas a processos. Dessa forma, compreender e avaliar a situação das variáveis que compõe o modelo de maturidade é fundamental para a proposição das ações de melhoria.

Nos últimos anos diversos autores, entre eles Harmon (2004) e Fischer (2004), propuseram modelos para avaliação da gestão dos processos de negócio baseados em níveis de maturidade (ROSEMANN; DE-BRUIN; HUEFFNER, 2004). Comforme Armistead e Pritchard (1999), a noção de maturidade está diretamente vinculada à expectativa de sucesso das iniciativas de gestão orientada a processos, quanto maior o nível de maturidade, maiores as chances de obter os benefícios decorrentes da orientação a processos de negócio.

Neste estudo, optou-se pela utilização do modelo de maturidade da orientação a processos de negócio (BPO -
Business Process Orientation) proposto por McCormack (2000). Este modelo busca avaliar 5 variáveis relativas a práticas de gestão orientada a processos. Três delas referem-se aos elementos básicos (visão, atividades e monitoração de processos) que compõe e definem as práticas de gestão de processos, enquanto as outras duas representam os resultados dessas práticas (superação de conflitos e coesão interdepartamental). McCormack (2000) estabelece 4 estágios de maturidade: ad hoc, definido, conectado e integrado. No estágio "Ad Hoc" os processos horizontais são pouco visíveis e a organização quase totalmente voltada para seus processos funcionais. No estágio seguinte ("Definido"), a visão funcional ainda é predo

minante, mas já começam a existir estruturas e métricas orientadas a processos. No estágio "Conectado" os processos de negócio estão bastante definidos e estruturados, quase equivalentes aos processos funcionais, mas ainda existem lacunas entre os processos. Finalmente no último estágio ("Integrado"), os processos horizontais estão totalmente definidos, não existem lacunas e a organização está estruturada de modo balanceado entre visão funcional e visão de processos.

\section{Procedimentos Metodológicos}

Esta pesquisa caracteriza-se como exploratória na medida em que buscou, a partir da utilização de uma ampla variedade de evidências, entender as práticas de gestão aplicadas, fatores organizacionais envolvidos e o desempenho percebido na empresa-objeto, estabelecendo relações entre essas variáveis, de modo a identificar oportunidades de melhorias a partir da aplicação de práticas de gestão orientadas a processos de negócio.

O Estudo de Caso, realizado junto a uma indústria do ramo de petróleo, buscou levantar informações sobre seus processos organizacionais, utilizando enfoque indu- 
Alberto Pavlick Caetani

Marinês Steffanello

tivo para análise dos dados coletados. Conforme Yin (2005), esta estratégia é particularmente adequada ao tipo de questão de pesquisa proposta, na medida em que, na avaliação de aspectos vinculados à gestão, por envolver múltiplos fatores interdependentes, tornase difícil perceber os limites entre fenômeno e o contexto onde o mesmo ocorre.

O processo de coleta de dados foi realizado através de pesquisa documental e da aplicação de questionários. Foram consultados e analisados documentos relativos ao planejamento estratégico da empresa, relatórios consolidados de desempenho e dados históricos referentes à execução de projetos estratégicos, metas e indicadores de desempenho. Para a coleta de dados foram adotados quatro questionários [IP-1, IP-2, IP-3 e IP-4] compostos de questões fechadas, aplicados de modo presencial junto a gestores e pessoas-chave identificadas por amostragem não probabilística, selecionada por tipicidade, considerando o envolvimento nos "processos orientados a clientes" definidos no Mapa de Processos da empresa.

Através do instrumento de pesquisa 1 (IP-1) buscou-se estabelecer uma visão do desempenho geral da empresa através da percepção de seus executivos, além de identificar as principais dificuldades para execução das ações estratégicas propostas. As questões relativas aos obstáculos estratégicos foram elaboradas a partir de síntese das contribuições de diversos autores (NEILSON; MARTIN; POWERS, 2008; HREBINIAK, 2006; MANKINS; STEELE, 2005; BEER; EISENSTAT, 2000; KAPLAN; NORTON, 1996), ponderadas conforme escala Likert de relevância com 5 pontos.

O IP-2 foi elaborado com o
Raquel Janissek-Muniz

Everton da Silveira Farias

objetivo de avaliar o grau de influência dos fatores organizacionais sobre $\mathrm{o}$ atingimento das metas estratégicas propostas, sendo selecionados os fatores organizacionais que condicionam ou são condicionados pelo modelo de gestão. No IP-2, os fatores organizacionais foram avaliados em relação à relevância (escala Likert de 5 pontos) e situação na empresa (impacto positivo, negativo ou nem positivo, nem negativo).

No IP-3 foram consolidados os principais benefícios esperados com a adoção de práticas de gestão orientadas a processos, de modo a avaliar sua relevância para a execução estratégica, assim como a percepção da situação atual destes benefícios na empresa.

E o IP-4 foi elaborado a partir de questionário adaptado de McCormack (1999) para avaliação das práticas de gestão orientadas a processos de negócio, sendo constituído de cinco grupos de questões avaliadas conforme escala Likert de concordância com 5 pontos. Os três primeiros grupos avaliam aspectos que caracterizam a gestão orientada a processos de negócio: visão de processo (3 questões), atividades de processo (3 questões) e monitoração de processos (5 questões). Os dois outros grupos avaliam os efeitos da gestão sobre a dinâmica interdepartamental, representada por aspectos de coesão (7 questões) e conflito (7 questões).

Para apoiar a análise dos dados foram estabelecidas relações entre os conceitos-chave do estudo (estratégia, gestão de processos, execução estratégia e desempenho) e as variáveis avaliadas nos quatro instrumentos de pesquisa, conforme esquema descrito na Figura 1, buscando-se efetivar a triangulação entre as percepções dos diferentes sujeitos consultados e os dados recolhidos na pesquisa documental. 
Gestão orientada a processos de negócio: oportunidades para melhoria da execução estratégica em uma refinaria de petróleo

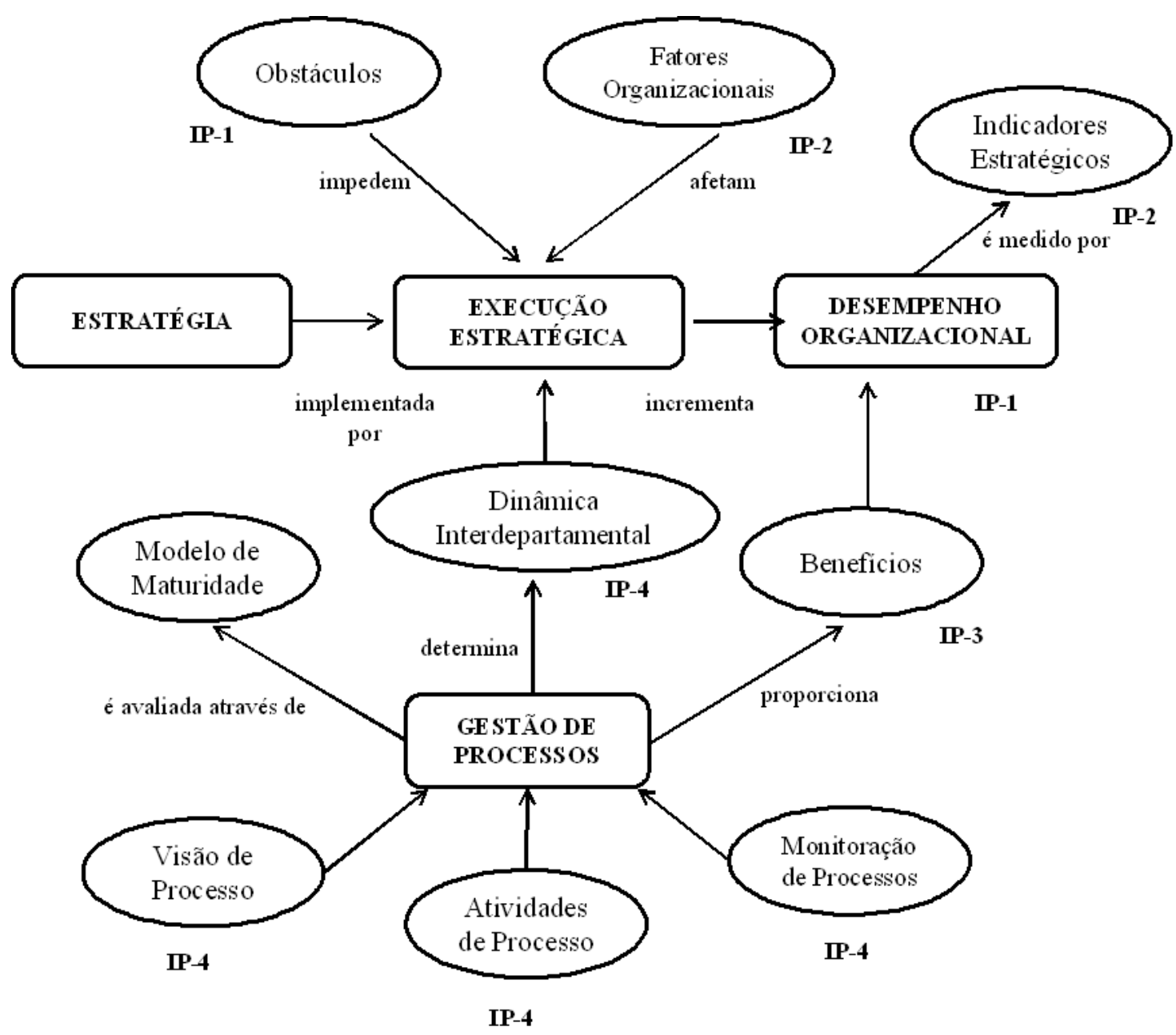

Figura 1. Relacionamento entre variáveis de pesquisa.

\section{Estudo de Caso}

A empresa desta pesquisa é uma empresa de energia de capital fechado, responsável pela produção de mais de 25 produtos derivados de petróleo, além da comercialização de biodiesel e energia elétrica, resultando em uma receita operacional bruta de mais de $\mathrm{R} \$ 10$ bilhões. A indústria do petróleo, por característica, é capital intensivo e integrada a uma complexa cadeia logística. A concorrência no mercado regional de derivados, tanto de outros refinadores e importadores, como de produtos substitutos (ex: álcool e gás natural), as restrições ao repasse aos preços internos das variações de custos por fatores externos (principalmente o preço internacional da matéria-prima e a cotação do dólar), além da complexidade envolvida na inserção em mercados externos, tornam essencial a implementação de estratégias para promover a competitividade e assegurar o crescimento sustentado da empresa (RIBEIRO, 2006).

O Planejamento Estratégico é o instrumento utilizado para a definição das principais diretrizes de longo prazo, sendo o mapa estratégico construído utilizando-se a metodologia do Balanced Scorecard.

Entre as variáveis acompanhadas no Balanced Scorecard, foram selecionados os indicadores estratégicos vinculados aos processos orientados ao cliente e que, conforme Ribeiro (2006) são representativos do desempenho na indústria do refino de petróleo: volume de vendas (volume total de derivados vendidos); satisfação dos clientes (índice apurado através de pesquisa anual); custo de refino (custo das operações industriais da 
refinaria, incluindo custos de pessoal, serviços de terceiros, materiais e insumos diversos, não considerando custos de matéria-prima e de energia consumida no processo industrial); margem bruta (faturamento líquido menos o custo do petróleo processado no período); indice de intensidade de energia (avalia a eficiência da utilização de energia nos processos industriais); fator de utilização total (taxa de utilização das unidades de Destilação em relação a sua capacidade nominal, considerando as perdas de processamento em função de problemas de confiabilidade, paradas de manutenção, folgas de programação, logística, etc.).

\subsection{Considerações sobre o desempenho}

A avaliação do desempenho organizacional é uma questão complexa e multifacetada para a qual concorrem fatores objetivos e subjetivos. Para fins deste trabalho buscou-se avaliar o desempenho a partir da percepção dos executivos, pois segundo Carneiro (2005), embora subjetiva, a avaliação dos executivos acaba incorporando diversos aspectos do desempenho, constituindo-se em alternativa válida para determinação do nível de desempenho de uma empresa.

Os executivos consultados mostra-
Raquel Janissek-Muniz Everton da Silveira Farias

ram-se francamente satisfeitos com o desempenho da empresa nos últimos dois anos. Conforme as respostas obtidas através do IP-1, tanto o desempenho geral, como o desempenho em relação a referenciais de excelência da indústria foram avaliados entre "BOM" e "MUITO BOM" por todos os executivos consultados. Considerando a importância do patrocínio e liderança da alta administração nos processos de mudança organizacional, o estabelecimento do nível de desempenho percebido é muito relevante para este estudo, pois, conforme Carneiro (2005, p. 160), "a forma como os executivos percebem e julgam o desempenho é um determinante de suas ações futuras".

A avaliação do comportamento histórico dos indicadores estratégicos oferece uma visão complementar do desempenho da empresa. Com exceção dos indicadores mais orientados à atividade industrial (Fator de Utilização e Índice de Intensidade de Energia), razoavelmente estáveis e muito próximos às metas estabelecidas, os demais indicadores apresentaram significativa oscilação ao longo dos últimos 30 meses (janeiro de 2008 a agosto de 2010), conforme pode ser observado na Figura 2.

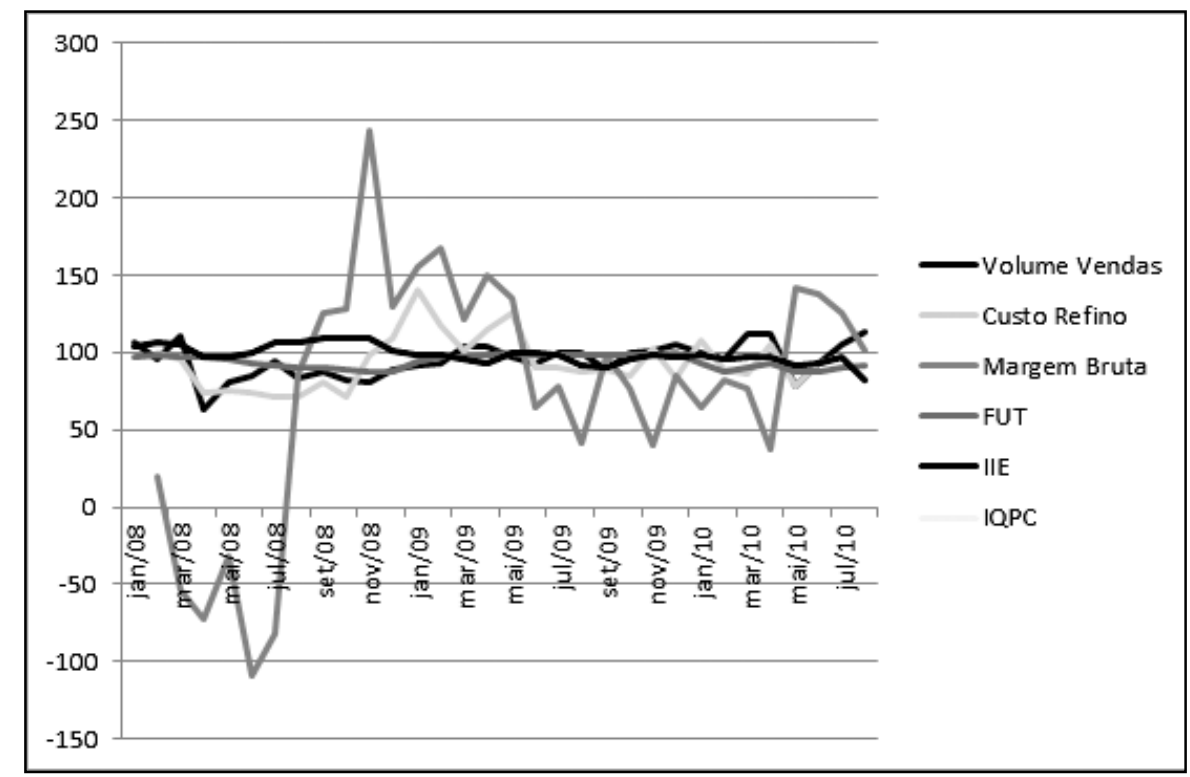

Figura 2. Evolução dos indicadores estratégicos. 
Gestão orientada a processos de negócio: oportunidades para melhoria da execução estratégica em uma refinaria de petróleo

Embora exista, por parte dos executivos, a clara percepção de um desempenho superior da empresa, esta avaliação não pôde ser corroborada, objetivamente, pela análise dos indicadores observados. Com exceção daqueles orientados à eficiência industrial, os demais indicadores, incluindo o lucro líquido, apresentaram comportamento bastante irregular, sem uma aparente vinculação com os resultados da execução estratégica. $\mathrm{O}$ conjunto dos dados analisados, no entanto, não foi suficiente para possibilitar uma compreensão mais ampla do fenômeno e de suas causas.

\subsection{Principais obstáculos à execução}

\section{estratégica}

A partir da percepção dos executivos (IP-1) e dos gestores dos indicadores estratégicos (IP-2) buscou-se identificar as principais dificuldades enfrentadas na empresa para implementar efetivamente as ações propostas em seu Planejamento Estratégico. $\mathrm{Na}$ consulta junto aos executivos, dos 14 obstáculos relacionados, apenas 4 foram citados como "muito relevantes", sem que se tenha verificado coincidências entre eles. Dos 5 executivos consultados, 2 deles não indicaram nenhum obstáculo nessa categoria, o que, de certa forma, está coerente com a avaliação positiva do desempenho da empresa.

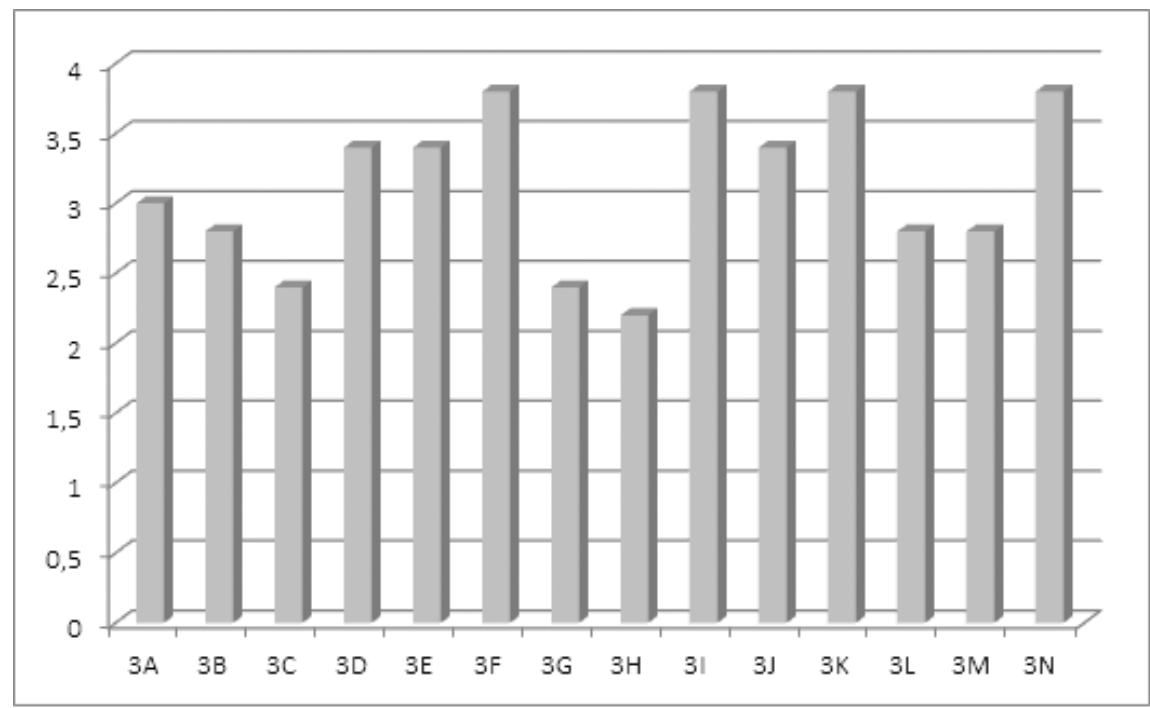

Figura 3. Obstáculos à execução da estratégia.

Considerando-se a média das percepções coletadas através do IP-1, indicadas na Figura 3, quatro obstáculos destacaram-se com o maior grau de relevância (média 3,8): deficiências na articulação de ações envolvendo múltiplas gerências $(3 \mathrm{~F})$; falta de compartilhamento de informações entre áreas (3I); insuficiência de feedback sobre a efetividade estratégica das ações (3K); falta de clareza na atribuição de responsabilidades pela tomada de decisão e implementação das ações (3N). Em sentido contrário, 3 itens destacaram-se pelo menor grau de relevância (média inferior a 2,5): falta de modelo para direcionamento dos esforços de implementação estratégica (3A); habilidades e competências inadequadas aos requerimentos da estratégia (3G); informações insuficientes para suportar a execução das ações (3I).

A partir da avaliação dos gestores responsáveis pelos indicadores estratégicos coletadas através do IP-2, foram identificados os fatores organizacionais de maior impacto para o atingimento das respectivas metas, ou seja, aqueles com maior impacto estratégico do fator organizacional: colabo- 
ração interdepartamental; fluxo de informações; capacitação das equipes; sistemas de informação. Em todos os casos o impacto foi considerado positivo, ou seja, na visão dos gestores dos indicadores todos os fatores organizacionais citados contribuem favoravelmente para a execução da estratégia.

A comparação entre a visão dos executivos e dos gestores permitiu a identificação de pontos em comum, mas também divergências importantes. Os obstáculos destacados pelos executivos com menor grau de relevância são coerentes com os impactos positivos dos fatores organizacionais citados pelos gestores, caracterizando que a empresa possui um conjunto de ferramentas de gestão adequado para suportar o processo de planejamento estratégico. No entanto, pôde-se observar divergências significativas em relação àqueles obstáculos julgados mais significativos pelos executivos. Deficiências na articulação de ações envolvendo múltiplas gerências e falta de compartilhamento de informações entre áreas muito provavelmente sejam resultado de um baixo nível de colaboração interdepartamental e de problemas envolvendo o fluxo de informações na empresa, fatores considerados positivos pelos responsáveis pelos indicadores estratégicos.

Embora não seja possível, a partir dos dados coletados na pesquisa, determinar a origem desta aparente contradição, algumas hipóteses podem ser utilizadas para explicá-la: a percepção da relevância dos obstáculos estratégicos está
Raquel Janissek-Muniz Everton da Silveira Farias

equivocada; a avaliação do impacto dos fatores organizacionais sobre os indicadores estratégicos está equivocada; os indicadores selecionados não são representativos da execução estratégica.

\subsection{Nível de maturidade na gestão orien- tada a processos}

McCormack (2000) alerta para a necessidade de aprofundar a análise dos dados além da simples totalização matemática dos itens do questionário, detalhando os resultados referentes tanto aos elementos que caracterizam a gestão orientada a processos (visão, atividades e monitoração de processos), quanto nos seus impactos sobre a organização (superação de conflitos e coesão interdepartamental). No modelo adotado, cada um dos elementos contribui de modo distinto para a maturidade da organização, de modo que a análise deve ser realizada tomando-se os resultados segregados por itens.

Conforme pode ser observado na Figura 4, o requisito básico para superar o estágio de maturidade "Ad Hoc" é obter, como resultado, pelo menos $50 \%$ dos pontos possíveis para o elemento visão de processo, porém este elemento, isoladamente, não consegue elevar a maturidade da organização para além do estágio "Definido". De modo análogo, como não faz sentido avaliar as atividades de processo e as iniciativas de monitoramento dos processos, sem que se tenha um razoável grau de visão de processos, a escala desses dois itens somente começa após o estágio "Definido". 
Gestão orientada a processos de negócio: oportunidades para melhoria da execução estratégica em uma refinaria de petróleo

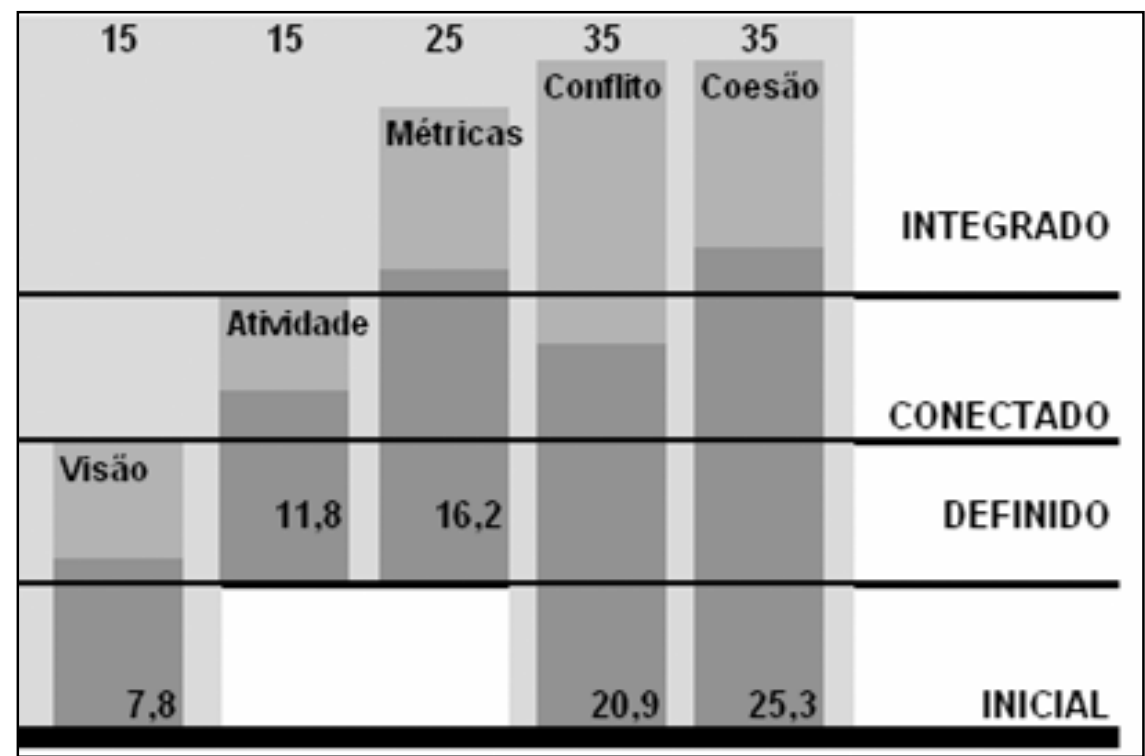

Figura 4. Modelo de Maturidade: detalhe por item.

Fonte: Adaptado de McCormack (2000).

Considerando que o modelo utilizado é evolutivo e cumulativo, ou seja, a passagem para um estágio superior somente se dá mediante o atingimento de todos os requisitos dos estágios anteriores, os dados obtidos na pesquisa nos permitem situar a empresa no estágio "Definido", mas com muito boas perspectivas de atingimento de estágios superiores, desde que consiga, logicamente, superar o gap localizado em "visão de processo".

\subsection{Análise dos elementos de maturidade}

Os resultados apurados nas primeiras 11 questões do IP-4, detalhados nas Figuras 5, 6 e 7, oferecem importante subsídio para entendimento do comportamento da empresa em relação a sua orientação a processos de negócio.

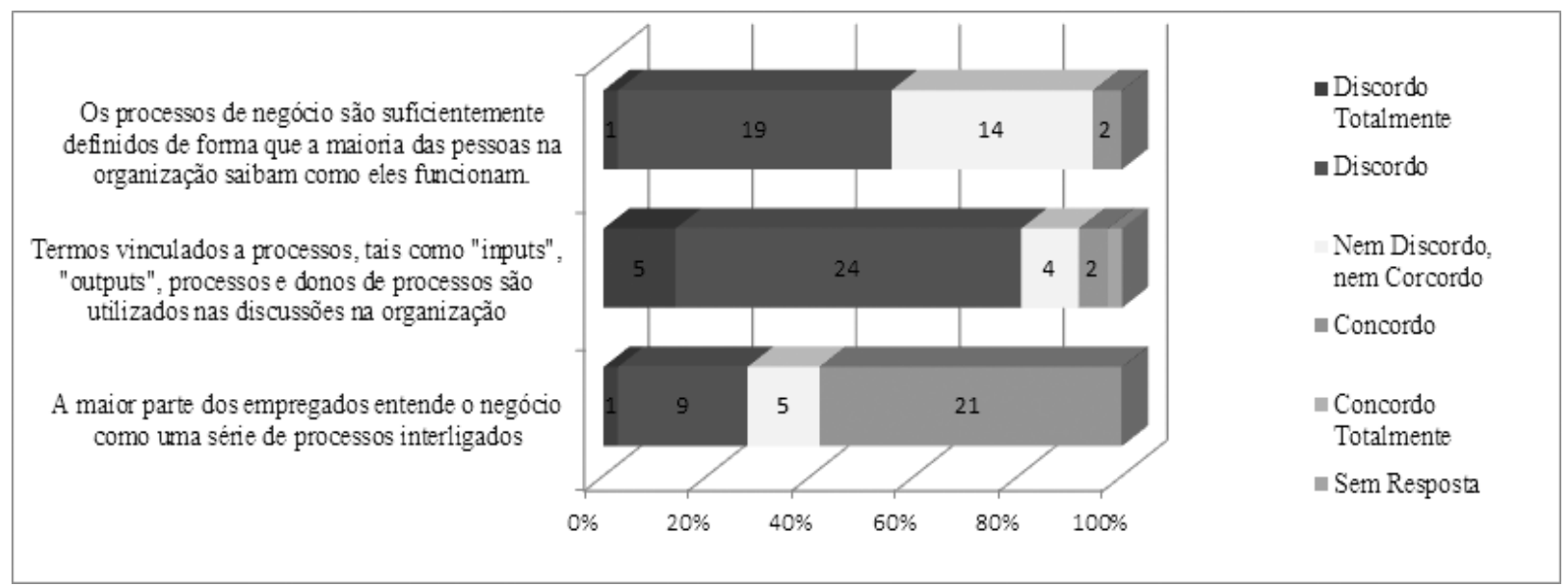

Figura 5. Visão de Processo.

A pontuação apurada para "Visão de Processo" foi a menor entre todos os elementos avaliados (grau 7,8 em 15 possíveis) e, com base na análise das respostas dadas às questões referentes a esse elemento, conforme a Figura 5, foi possível inferir que:

a) Os empregados, de uma forma geral, não conhecem os processos de negócio, ou pelo menos não de modo amplo e integrado; 
Alberto Pavlick Caetani

Marinês Steffanello

b) As discussões formais envolvendo modelos de processos são raras ou restritas a pequenos grupos na empresa;

c) As pessoas percebem a existência dos processos e sua importância para o negócio da empresa, mas não têm conhecimento de como eles funcionam ou deveriam funcionar.

No sentido contrário, as questões apresentadas na Figura 6, referentes às
Raquel Janissek-Muniz

Everton da Silveira Farias

atividades em processo, foram aquelas nas quais se observou a maior pontuação, indicando que, de uma maneira geral, as atividades desenvolvidas na empresa são multidimensionais e envolvem aplicação de conhecimento e de técnicas de solução de problemas. As pessoas entendem a importância e a complexidade envolvida em suas atividades, mas, a julgar pelos resultados relativos à visão de processo, não conseguem perceber, de maneira clara e objetiva, qual a contribuição do seu trabalho para os resultados da empresa.

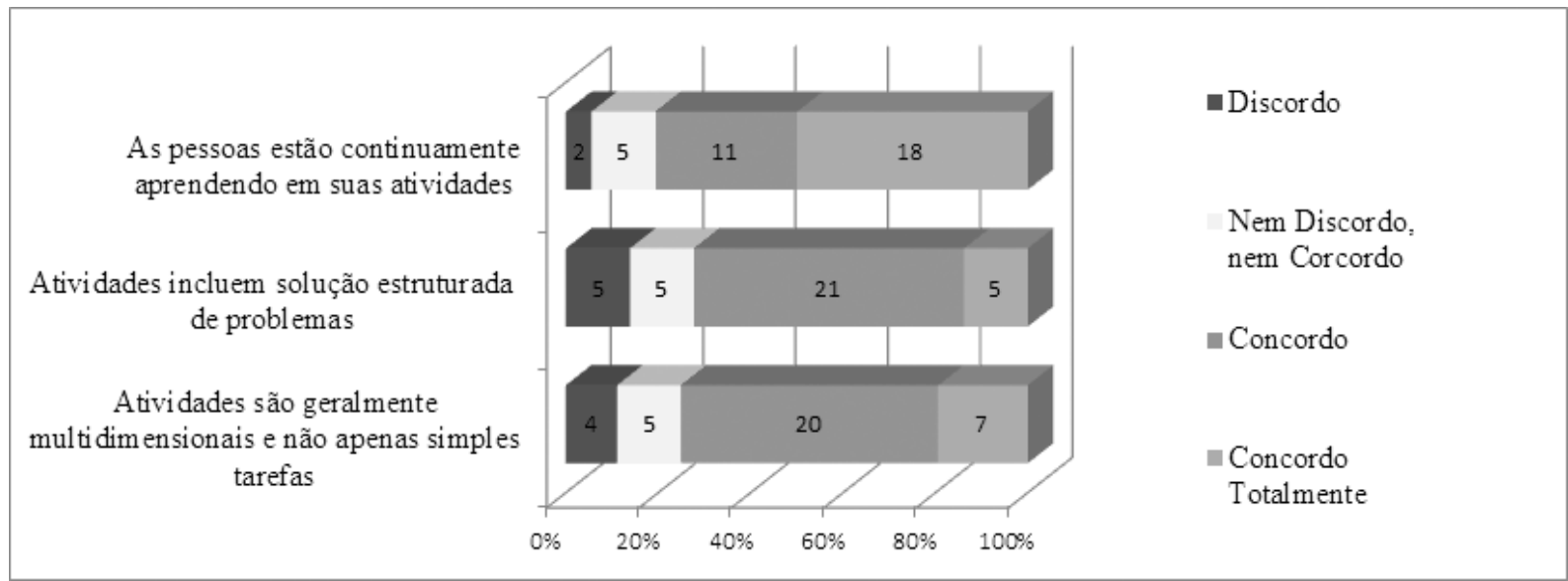

Figura 6. Atividades em Processo.

Conforme pode ser observado na Figura 7 , as respostas dadas às questões referentes ao gerenciamento e monitoração dos processos, avaliadas em conjunto com as informações relativas ao Planejamento Estratégico e à sistemática de acompanhamento de desempenho, demonstram que:

a) As pessoas de uma forma geral reconhecem a existência e acompanhamento de indicado- res de desempenho, e que estes indicadores estão relacionados a processos e não a simples atividades;

b) As metas de desempenho, embora estabelecidas, não são conhecidas por parte significativa das pessoas;

c) Não existe uma percepção clara dos resultados dos processos.

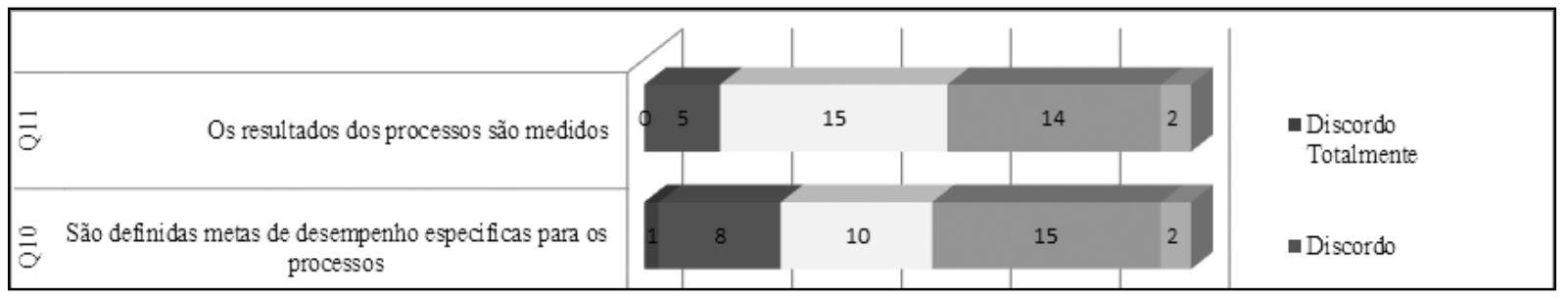


Gestão orientada a processos de negócio: oportunidades para melhoria da execução estratégica em uma refinaria de petróleo

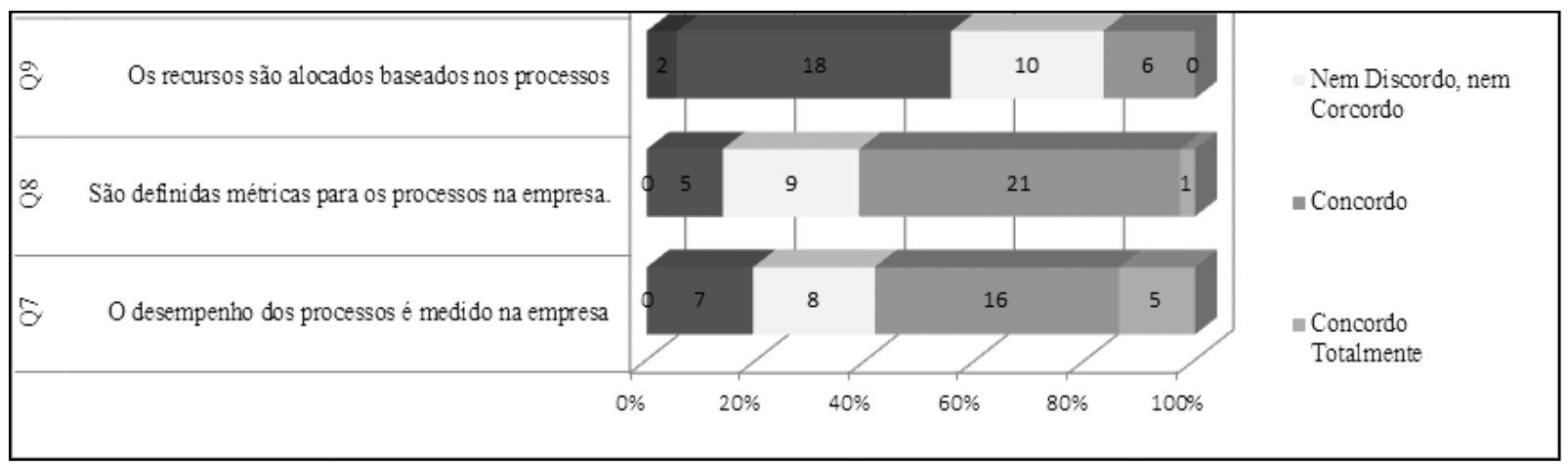

Figura 7. Monitoração de Processos.

A grande proporção de respostas "Nem concordo, nem discordo" na Figura 7, significativamente maior que nas duas dimensões avaliadas anteriormente, parece refletir um comportamento não uniforme entre as diversas áreas da empresa, ou seja, os esforços de monitoração de desempenho e resultados dos processos provavelmente estejam mais desenvolvidos em determinadas áreas do que em outras. Esta discrepância pode, inclusive, sugerir que a monitoração esteja sendo realizada de forma mais estruturada nos processos intrafuncionais, com entradas e saídas restritas a uma mesma área ou departamento.

\subsection{Características do modelo de gestão da empresa}

As informações obtidas através dos instrumentos de pesquisa nos permitiram identificar algumas das práticas correntes na empresa e assim caracterizar o modelo de gestão implementado, ou seja, o comjunto de escolhas realizadas pelos executivos para definir objetivos, motivar pessoas, coordenar atividades e alocar recursos (BIRKINSHAW; GODDARD, 2009). As 14 questões da parte final do IP4, detalhadas nas Figuras 8 e 9, referem-se à percepção de aspectos relacionados à dinâmica interdepartamental, ou seja, ao modo de atuação das pessoas na empresa.

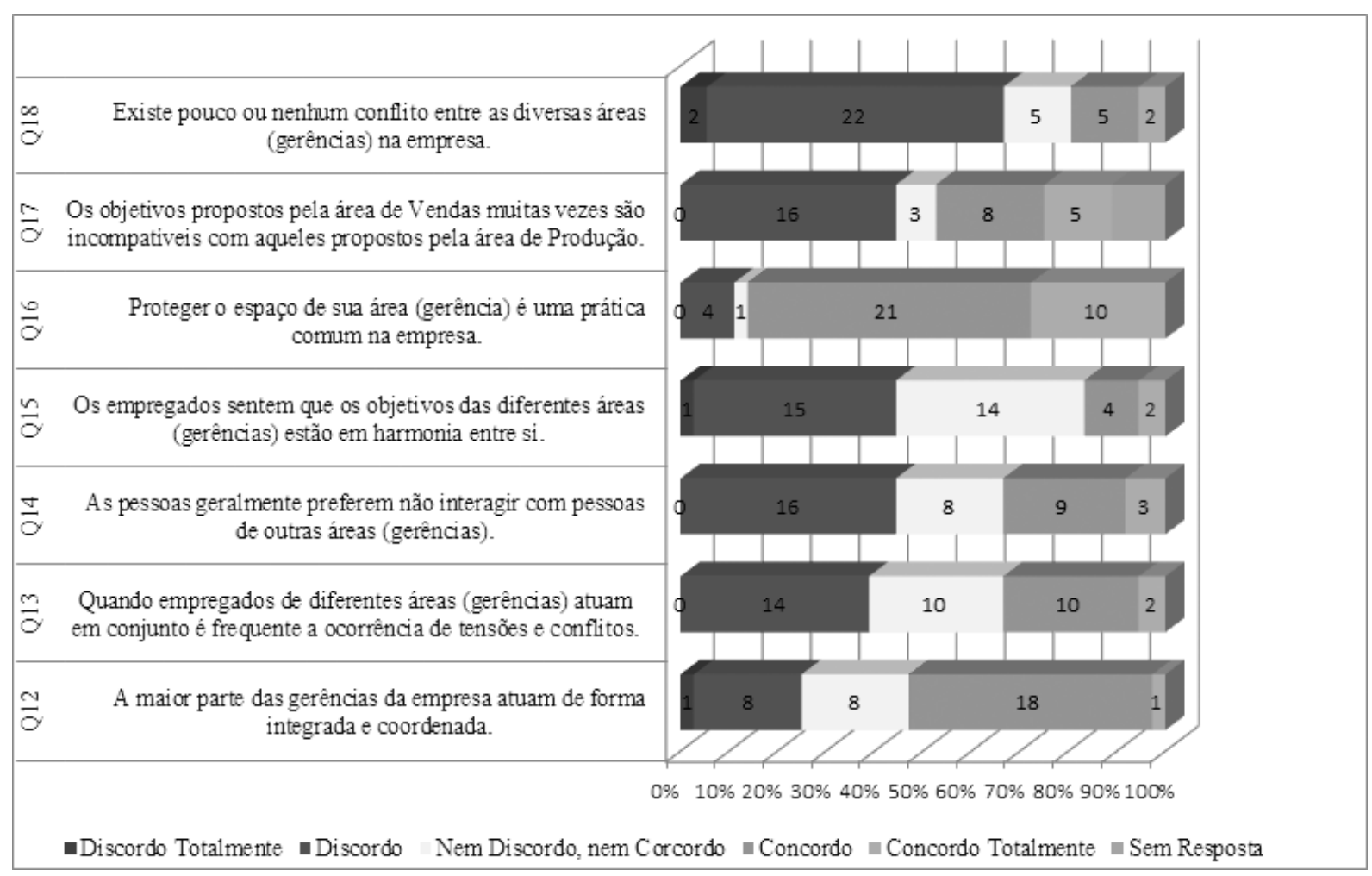

Figura 8. Conflito interdepartamental 


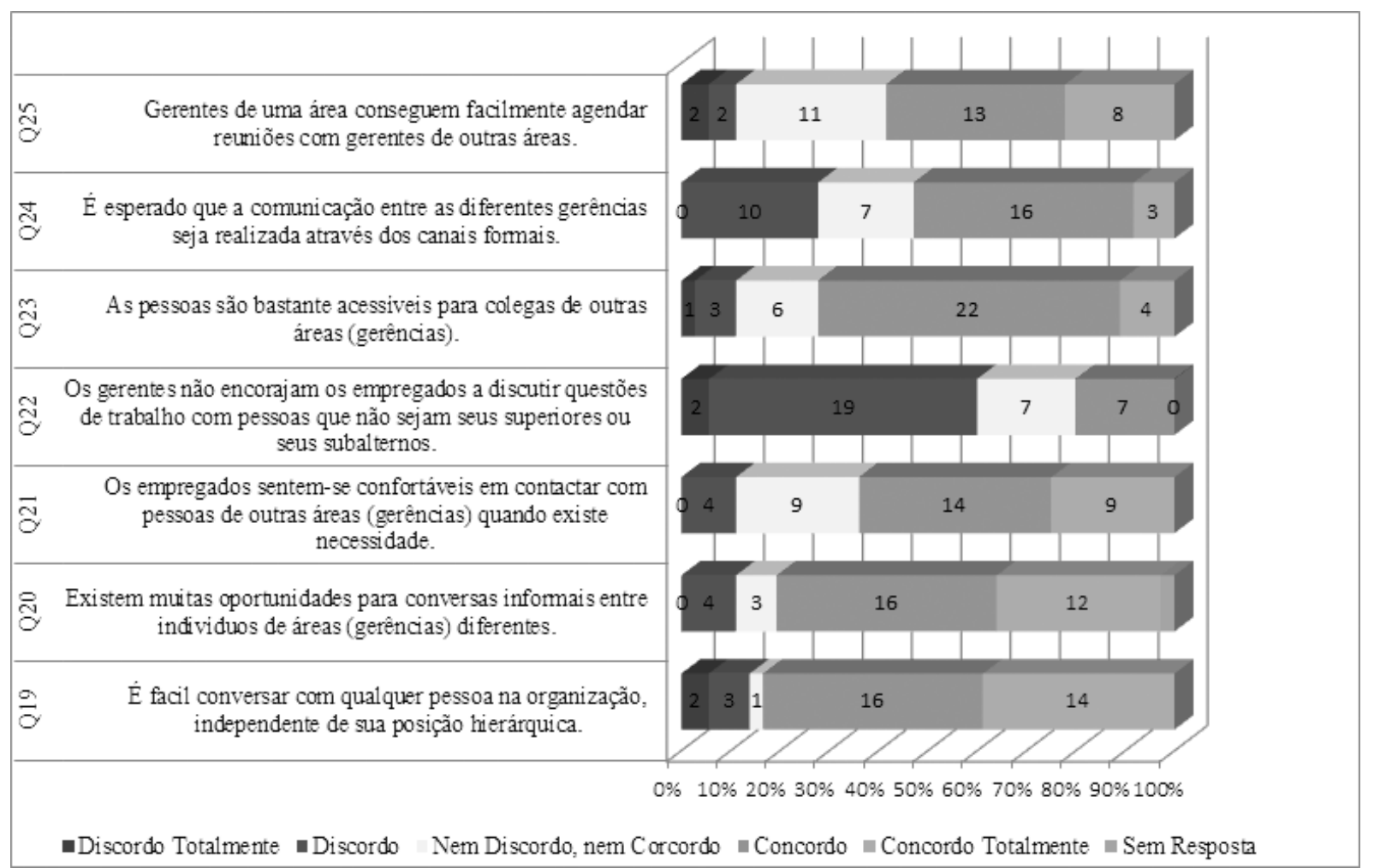

Figura 9. Coesão interdepartamental

Considerando as informações levantadas nesta pesquisa e as características que diferenciam os modelos de gestão, a empresa estudada apresenta um claro predomínio da lógica funcional sobre a lógica orientada aos processos de negócio. Além das deficiências apontadas na visão de processo, a orientação funcional predominante na empresa pode ser melhor percebida através dos seguintes aspectos, identificados em questões do IP4:

a) Alocação de recursos não vinculada aos processos de negócio;

b) Objetivos das diversas áreas percebidos como contraditórios;

c) Resultados dos processos de negócio não medidos de modo sistemático;

d) Existência de situações de conflitos (ausência de harmonia) entre as áreas;

e) Existência de situações de conflito quando empregados de di- ferentes áreas necessitam atuar em conjunto;

f) Foco no interesse específico das áreas através da disseminação da prática de proteção dos espaços funcionais.

\subsection{Relações nos processos orientados a clientes}

Elaborado para avaliação das práticas de gestão orientadas a processos de negócio, e constituído de cinco grupos de questões, o IP-4 permitiu avaliar aspectos que caracterizam a gestão orientada a processos de negócio (visão de processo, atividades de processo, monitoração de processos) e os efeitos da gestão sobre a dinâmica interdepartamental, representada por aspectos de coesão e conflito. A partir das respostas válidas dadas às 25 questões que $\mathrm{o}$ compõem, e considerando o total dos respondentes (36, dos quais 20 técnicos e 16 gerentes), a independência entre os aspectos avaliados no IP-4 pode ser confirmada pelos baixos índices de 
Gestão orientada a processos de negócio: oportunidades para melhoria da execução estratégica em uma refinaria de petróleo

correlação entre as questões, conforme figuras 10 e 11 .

\begin{tabular}{|c|c|c|c|c|c|c|c|c|c|c|c|c|c|c|c|c|c|c|c|c|c|c|c|c|c|c|}
\hline \multicolumn{27}{|c|}{ MATRIZ DE CORRELAÇÄO ENTRE AS QUESTÖES - IP4 } \\
\hline & \begin{tabular}{|l|}
01 \\
\end{tabular} & Q2 & 03 & 04 & \begin{tabular}{|l|}
05 \\
\end{tabular} & 06 & Q7 & 08 & Q9 & 010 & Q11 & 01 & & \begin{tabular}{|l|l|}
13 \\
\end{tabular} & 014 & Q15 & Q16 & Q17 & 018 & Q19 & 020 & Q21 & Q22 & Q23 & Q 24 & 025 \\
\hline 01 & 1,00 & \begin{tabular}{|l|l}
0,01 \\
\end{tabular} & 0,15 & 0,06 & $-0,11$ & 0,08 & 0,12 & 0,16 & 0,23 & 0,05 & $-0,00$ & 0,1 & & $1,09-$ & $-0,16$ & 0,25 & 0,08 & 0,13 & 0,23 & $-0,03$ & \begin{tabular}{l|l}
3 & $-0,30$ \\
\end{tabular} & $-0,25$ & $-0,25$ & 0,04 & 0,26 & $-0,01$ \\
\hline 02 & & \begin{tabular}{|l|}
1,00 \\
\end{tabular} & 0,29 & $-0,02$ & $-0,10$ & 0,10 & 0,36 & 0,56 & 0,41 & 0,36 & 0,41 & 0,0 & & $1,09-$ & $-0,37$ & $-0,24$ & 0,01 & 0,12 & 0,06 & 0,07 & \begin{tabular}{l|l}
7 & 0,04
\end{tabular} & $\mid-0,06$ & \begin{tabular}{|l|l|}
0,17 \\
\end{tabular} & 0,00 & $-0,08$ & 0,31 \\
\hline 03 & & & 1,00 & 0,09 & $-0,11$ & 0,08 & 0,27 & 0,25 & 0,18 & $-0,01$ & $-0,0$ & 0,0 & & $1,09-$ & $-0,15$ & 0,20 & 0,12 & 0,04 & 0,09 & $-0,02$ & $2-0,07$ & $-0,06$ & $-0,07$ & $-0,09$ & $-0,10$ & 0,13 \\
\hline 04 & & & & 1,00 & \begin{tabular}{|l|}
0,49 \\
\end{tabular} & 0,20 & 0,04 & 0,21 & 0,05 & 0,18 & 0,17 & $-0,2$ & & $1,14-$ & $-0,18$ & $-0,09$ & 0,14 & $-0,07$ & $-0,03$ & $-0,20$ & $0,0,11$ & $-0,32$ & $-0,15$ & $-0,14$ & 0,26 & $-0,07$ \\
\hline 05 & & & & & 1,00 & 0,38 & 0,11 & 0,08 & $-0,06$ & $-0,02$ & 0,07 & $-0,1$ & & $1,03-$ & $-0,40$ & $-0,05$ & 0,21 & $-0,02$ & $-0,28$ & $-0,42$ & $2-0,34$ & $-0,45$ & $-0,20$ & $-0,48$ & 0,25 & 0,10 \\
\hline 06 & & & & & & \begin{tabular}{|l|}
1,00 \\
\end{tabular} & $-0,22$ & 0,06 & 0,15 & 0,19 & 0,23 & $-0,0$ & & , 16- & $-0,13$ & 0,01 & 0,04 & $-0,02$ & $-0,21$ & $-0,20$ & $-0,34$ & $-0,16$ & \begin{tabular}{|l|l|}
0,13 \\
\end{tabular} & \begin{tabular}{|l|l|}
$-0,12$ \\
\end{tabular} & 0,19 & 0,12 \\
\hline 07 & & & & & & & \begin{tabular}{|l|}
1,00 \\
\end{tabular} & 0,55 & 0,40 & 0,37 & 0,3 & 0,1 & & $1,06-$ & $-0,10$ & \begin{tabular}{|l|l|}
0,12 \\
\end{tabular} & 0,19 & 0,11 & 0,03 & 0,04 & \begin{tabular}{l|l}
4 & 0,15 \\
\end{tabular} & 0,13 & $-0,06$ & $-0,01$ & 0,01 & 0,16 \\
\hline 08 & & & & & & & & 1,00 & 0,39 & 0,63 & 0,58 & 0,1 & & $1,04-$ & $-0,16$ & 0,10 & $-0,02$ & 0,07 & \begin{tabular}{|l|l}
0,17 \\
\end{tabular} & 0,15 & \begin{tabular}{|l|l|}
5 & 0,22 \\
\end{tabular} & $-0,12$ & 0,09 & \begin{tabular}{|c|}
$-0,02$ \\
\end{tabular} & $-0,07$ & 0,22 \\
\hline 09 & & & & & & & & & 1,00 & 0,56 & 0,58 & 0,2 & & 1,18 & $-0,05$ & 0,07 & 0,10 & 0,22 & 0,02 & 0,22 & $2-0,02$ & 0,09 & 0,10 & 0,16 & 0,02 & 0,26 \\
\hline Q10 & & & & & & & & & & 1,00 & 0,80 & 0,3 & & 1,09 & 0,19 & 0,07 & $-0,09$ & 0,10 & 0,07 & 0,20 & \begin{tabular}{|l|l}
0,23 \\
\end{tabular} & $-0,03$ & 0,29 & 0,22 & 0,03 & 0,03 \\
\hline Q11 & & & & & & & & & & & 1,00 & 0,3 & & 1,15 & 0,23 & $-0,03$ & $-0,15$ & 0,12 & $-0,03$ & 0,27 & \begin{tabular}{l|l}
0,26 \\
7
\end{tabular} & 0,15 & 0,41 & 0,24 & $-0,13$ & 0,09 \\
\hline 012 & & & & & & & & & & & & 1,0 & & 1,28 & 0,43 & 0,22 & $-0,06$ & \begin{tabular}{|l|l}
0,13 \\
\end{tabular} & $-0,07$ & 0,29 & \begin{tabular}{l|l}
9,35 \\
\end{tabular} & 0,10 & 0,36 & 0,41 & $\mid-0,08$ & 0,10 \\
\hline 013 & & & & & & & & & & & & & & , 00 & 0,32 & 0,30 & 0,03 & 0,20 & 0,39 & 0,24 & \begin{tabular}{|l|l|}
4 & 0,00 \\
\end{tabular} & 0,00 & $-0,10$ & 0,34 & $-0,06$ & $-0,08$ \\
\hline Q14 & & & & & & & & & & & & & & & 1,00 & \begin{tabular}{|l|}
0,28 \\
\end{tabular} & $-0,25$ & 0,10 & $-0,01$ & 0,37 & $\begin{array}{ll}0,44 \\
7\end{array}$ & 0,33 & 0,24 & 0,42 & $-0,30$ & $-0,22$ \\
\hline Q15 & & & & & & & & & & & & & & & & 1,00 & 0,24 & 0,07 & \begin{tabular}{|l|l}
0,47 \\
\end{tabular} & 0,34 & \begin{tabular}{|l|l}
4 & 0,04
\end{tabular} & 0,16 & $-0,05$ & 0,26 & $-0,13$ & 0,29 \\
\hline 016 & & & & & & & & & & & & & & & & & \begin{tabular}{|l|}
1,00 \\
\end{tabular} & $-0,05$ & 0,15 & $-0,14$ & $4-0,24$ & 0,26 & \begin{tabular}{|l|l|}
0,17 \\
\end{tabular} & 0,03 & 0,29 & 0,29 \\
\hline Q17 & & & & & & & & & & & & & & & & & & \begin{tabular}{|l|}
1,00 \\
\end{tabular} & 0,16 & 0,23 & \begin{tabular}{|l|l|}
3 & 0,20
\end{tabular} & $-0,07$ & 0,26 & 0,37 & 0,27 & 0,22 \\
\hline 018 & & & & & & & & & & & & & & & & & & & 1,00 & 0,29 & $-0,14$ & $-0,05$ & $-0,07$ & 0,25 & $-0,05$ & 0,18 \\
\hline 019 & & & & & & & & & & & & & & & & & & & & 1,00 & 0,37 & 0,53 & 0,36 & 0,72 & 0,01 & 0,03 \\
\hline 020 & & & & & & & & & & & & & & & & & & & & & 1,00 & 0,29 & 0,31 & 0,35 & $-0,30$ & $-0,02$ \\
\hline 021 & & & & & & & & & & & & & & & & & & & & & & 1,00 & 0,57 & 0,52 & $-0,08$ & 0,09 \\
\hline 022 & & & & & & & & & & & & & & & & & & & & & & & 1,00 & 0,54 & 0,17 & 0,14 \\
\hline 023 & & & & & & & & & & & & & & & & & & & & & & & & 1,00 & 0,14 & 0,15 \\
\hline Q24 & & & & & & & & & & & & & & & & & & & & & & & & & 1,00 & 0,02 \\
\hline 025 & & & & & & & & & & & & & & & & & & & & & & & & & & 1,00 \\
\hline
\end{tabular}

Figura 10. Matriz de Correlação - IP4: Todos os Respondentes

Já os altos índices de correlação observados nas respostas dos gerentes às questões relativas à monitoração de processos (figura 11) reforçam uma visão segmentada da empresa, orientada às funções, compartilhada e reproduzida pelo corpo gerencial.

\begin{tabular}{|c|c|c|c|c|c|c|c|c|c|c|c|c|c|c|c|c|c|c|c|c|c|c|c|c|c|}
\hline \multicolumn{26}{|c|}{ MATRIZ DE CORRELAÇÄO ENTRE AS QUESTÖES - IP4 } \\
\hline & 01 & Q2 & Q3 & Q4 & 05 & \begin{tabular}{|l|}
06 \\
\end{tabular} & Q7 & 08 & Q9 & Q10 & Q11 & Q12 & Q13 & Q14 & Q15 & Q16 & Q17 & Q18 & Q19 & Q20 & Q21 & Q22 & 023 & Q24 & 025 \\
\hline Q1 & 1,00 & $-0,22$ & 0,07 & 0,32 & $-0,03$ & 0,05 & 0,00 & $-0,09$ & $-0,35$ & $-0,0$ & $-0,22$ & 0,00 & $-0,08$ & $-0,20$ & 0,10 & $-0,16$ & $-0,40$ & 0,12 & $-0,40$ & $-0,25$ & $-0,46$ & $-0,51$ & $-0,31$ & 0,25 & $-0,46$ \\
\hline \begin{tabular}{|l|l|} 
\\
\end{tabular} & & 1,00 & 0,18 & $-0,10$ & $-0,06$ & $-0,26$ & 0,53 & 0,71 & 0,37 & 0,4 & 0,50 & $-0,11$ & $-0,34$ & $-0,54$ & $-0,22$ & $-0,28$ & 0,22 & 0,38 & 0,27 & 0,24 & $-0,04$ & 0,14 & $-0,06$ & $-0,36$ & 0,49 \\
\hline \begin{tabular}{|l|l|} 
Q3 \\
\end{tabular} & & & 1,00 & 0,08 & $-0,15$ & $-0,05$ & 0,38 & 0,17 & 0,05 & 0,0 & 0,01 & 0,44 & $-0,13$ & 0,09 & 0,35 & 0,05 & $-0,11$ & 0,01 & 0,20 & $-0,13$ & 0,11 & 0,12 & 0,03 & 0,18 & $-0,17$ \\
\hline \begin{tabular}{|l|l|}
$\mathrm{Q}$ \\
\end{tabular} & & & & 1,00 & 0,56 & 0,18 & 0,29 & 0,22 & 0,21 & 0,2 & 0,33 & 0,24 & 0,35 & $-0,11$ & $-0,16$ & 0,28 & $-0,05$ & $-0,47$ & $-0,17$ & 0,02 & $-0,28$ & $-0,16$ & 0,08 & 0,33 & 0,06 \\
\hline \begin{tabular}{|l|}
05 \\
\end{tabular} & & & & & 1,00 & 0,48 & 0,36 & 0,32 & 0,25 & 0,2 & 0,48 & 0,09 & 0,11 & $-0,24$ & 0,05 & 0,22 & 0,05 & $-0,75$ & $-0,21$ & $-0,11$ & $-0,37$ & 0,05 & $-0,33$ & 0,15 & 0,03 \\
\hline \begin{tabular}{|l|l|}
06 \\
\end{tabular} & & & & & & 1,00 & 0,08 & 0,00 & $-0,23$ & $-0,0$ & 0,14 & $-0,13$ & 0,16 & 0,24 & 0,29 & 0,31 & 0,14 & $-0,46$ & $-0,28$ & $-0,05$ & 0,07 & 0,16 & $-0,20$ & $-0,01$ & $-0,15$ \\
\hline \begin{tabular}{|l|l|} 
Q7 \\
\end{tabular} & & & & & & & 1,00 & 0,82 & 0,5 & 0,7 & 0,85 & 0,42 & $-0,07$ & $-0,21$ & $-0,06$ & 0,00 & 0,35 & $-0,13$ & 0,08 & 0,28 & 0,04 & 0,26 & 0,09 & 0,16 & 0,26 \\
\hline \begin{tabular}{|l|l|}
08 \\
\end{tabular} & & & & & & & & 1,00 & 0,46 & 0,6 & 0,78 & 0,34 & $-0,19$ & $-0,46$ & $-0,08$ & 0,00 & 0,29 & $-0,06$ & 0,11 & 0,48 & 0,05 & 0,35 & 0,00 & $-0,04$ & 0,61 \\
\hline \begin{tabular}{|l|}
09 \\
\end{tabular} & & & & & & & & & 1,00 & 0,8 & 0,79 & 0,25 & 0,27 & $-0,13$ & $-0,29$ & 0,10 & 0,51 & $-0,05$ & 0,44 & 0,27 & 0,16 & 0,30 & 0,48 & 0,11 & 0,15 \\
\hline Q10 & & & & & & & & & & 1,0 & 0,87 & 0,31 & 0,13 & $-0,19$ & $-0,36$ & 0,33 & 0,56 & 0,07 & 0,04 & 0,29 & 0,02 & 0,39 & 0,22 & 0,18 & 0,23 \\
\hline Q11 & & & & & & & & & & & 1,00 & 0,26 & 0,11 & $-0,16$ & $-0,14$ & 0,13 & 0,53 & $-0,21$ & 0,10 & 0,37 & 0,10 & 0,36 & 0,19 & 0,01 & 0,38 \\
\hline Q12 & & & & & & & & & & & & 1,00 & 0,53 & 0,31 & 0,27 & 0,20 & 0,01 & $-0,19$ & 0,04 & 0,32 & 0,06 & 0,28 & 0,40 & 0,14 & 0,10 \\
\hline Q13 & & & & & & & & & & & & & 1,00 & 0,57 & 0,11 & 0,17 & $-0,05$ & $-0,19$ & $-0,09$ & 0,09 & $-0,12$ & $-0,07$ & 0,46 & $-0,14$ & 0,00 \\
\hline Q14 & & & & & & & & & & & & & & 1,00 & 0,42 & 0,25 & $-0,01$ & $-0,09$ & $-0,14$ & $-0,04$ & 0,36 & 0,10 & 0,39 & $-0,11$ & $-0,12$ \\
\hline Q15 & & & & & & & & & & & & & & & 1,00 & $-0,22$ & $-0,31$ & $-0,35$ & $-0,07$ & $-0,04$ & 0,15 & 0,01 & $-0,14$ & $-0,30$ & $-0,10$ \\
\hline Q16 & & & & & & & & & & & & & & & & 1,00 & 0,26 & $-0,05$ & $-0,23$ & $-0,17$ & 0,05 & 0,50 & 0,00 & 0,43 & 0,00 \\
\hline Q17 & & & & & & & & & & & & & & & & & 1,00 & 0,02 & 0,19 & 0,57 & 0,37 & 0,77 & 0,28 & 0,22 & 0,04 \\
\hline Q18 & & & & & & & & & & & & & & & & & & 1,00 & 0,13 & $-0,08$ & 0,01 & $-0,01$ & 0,10 & $-0,08$ & $-0,02$ \\
\hline Q19 & & & & & & & & & & & & & & & & & & & 1,00 & 0,40 & 0,62 & 0,26 & 0,63 & 0,14 & 0,21 \\
\hline Q20 & & & & & & & & & & & & & & & & & & & & 1,00 & 0,55 & 0,50 & 0,57 & $-0,06$ & 0,50 \\
\hline Q21 & & & & & & & & & & & & & & & & & & & & & 1,00 & 0,51 & 0,63 & 0,16 & 0,37 \\
\hline Q22 & & & & & & & & & & & & & & & & & & & & & & 1,00 & 0,21 & 0,28 & 0,24 \\
\hline Q23 & & & & & & & & & & & & & & & & & & & & & & & 1,00 & 0,08 & 0,21 \\
\hline Q24 & & & & & & & & & & & & & & & & & & & & & & & & 1,00 & $-0,25$ \\
\hline Q25 & & & & & & & & & & & & & & & & & & & & & & & & & 1,00 \\
\hline
\end{tabular}

Figura 11. Matriz de Correlação - IP4: Apenas Gerentes

Revista de Negócios, ISSN 1980-4431, Blumenau, Brasil, v. 18, n. 4, p. 33-54, Outubro/Dezembro de 2013 
Alberto Pavlick Caetani

Marinês Steffanello
Raquel Janissek-Muniz

Everton da Silveira Farias

\subsection{Oportunidades e desafios}

Embora a empresa estudada apresente, conforme avaliação de seus executivos, um desempenho bastante positivo, os resultados apurados nesta pesquisa indicaram amplas possibilidades de melhorias. Submetidos à avaliação dos gestores através do IP-3, todos os benefícios citados na literatura como decorrentes da adoção de práticas de gestão orientadas a processos foram considerados relevantes, sendo indicado que boa parte deles encontra-se em fase incipiente ou mesmo inexistem na empresa.

A vinculação do gerenciamento de desempenho aos resultados empresariais conforme definido nos processos de negócio, e não a funções isoladas, foi considerado muito relevante por $76 \%$ dos gerentes consultados, sendo que $65 \%$ deles avaliaram que esta prática não é atualmente aplicada ou está em estágio inicial na empresa. Além de coerente com a percepção de metade dos empregados não ocupantes de função gerencial que responderam não concordar com a assertiva "são definidas metas de desempenho específicas para os processos" (questão 10 do IP-4), este aspecto relaciona-se fortemente com um dos principais obstáculos estratégicos percebidos pelos executivos ("ausência ou insuficiência de feedback sobre a efetividade estratégica das ações"). Cabe destacar que esta deficiência muito provavelmente não seja determinada pelo sistema adotado pela empresa para medição do desempenho, fator organizacional considerado de impacto positivo pelos gestores dos indicadores estratégicos.

Outro aspecto considerado muito relevante por $76 \%$ dos gerentes foi a utilização de modelo de processos como forma de divulgar e facilitar o entendimento das operações da empresa, sendo que $41 \%$ deles não reconhece a adoção dessa prática na empresa. A ausência de discussões formais e estruturadas envolvendo modelos de processos foi reconhecida por cerca de $70 \%$ dos gerentes e $90 \%$ dos empregados consultados. Deficiências na definição dos processos de negócio com certeza contribuem para a falta de clareza na atribuição de responsabilidades pela tomada de decisão e implementação das ações, considerado um dos principais obstáculos enfrentado pela empresa para implementar sua estratégia de negócio.

Finalmente, quase $60 \%$ dos gerentes declararam ser muito relevante que a empresa ajuste sua estrutura organizacional de modo a otimizar a cadeia de valor, maximizando os resultados dos processos orientados ao cliente (e não as funções isoladamente) e mais da metade deles avaliaram que a estrutura atual não possui os atributos necessários para maximizar os resultados dos processos críticos. Considerando que os gestores dos indicadores estratégicos não tenham apontado a estrutura organizacional atual como um fator relevante para atingimento das suas metas estratégicas e que os executivos não tenham reportado conflitos entre intenção estratégica e estrutura de poder, a percepção de deficiências na articulação de ações envolvendo múltiplas gerências (citada como importante obstáculo estratégico) pode ser interpretada como decorrência de problemas, não na estrutura organizacional, mas na organização dos processos.

A partir do levantamento dos principais obstáculos enfrentados pela empresa para implementar sua estratégia e dos fatores organizacionais com maior impacto sobre os indicadores estratégicos vinculados aos processos de negócio, foi possível identificar oportunidades para melhoria do desempenho da empresa a partir da aplicação de práticas de gestão orientadas a processos. Cabe destacar que a empresa dispõe de importantes instrumentos de gestão para implementar e desdobrar suas estratégias de negócio, tais 
Gestão orientada a processos de negócio: oportunidades para melhoria da execução estratégica em uma refinaria de petróleo

como objetivos estratégicos de longo prazo, indicadores balanceados de desempenho (Balanced Scorecard), monitoração da execução estratégica, sistemática de gerenciamento de desempenho individual e um abrangente Sistema de Gestão de Qualidade.

\subsection{Ações de melhoria}

As iniciativas propostas neste estudo visam aumentar o grau de maturidade da empresa na gestão dos seus processos através da consolidação de uma visão de processo compartilhada por toda a empresa. Embora a visão de processo isoladamente não produza impactos diretos significativos sobre o desempenho organizacional, constitui a base essencial para a organização das atividades e definição das métricas que irão suportar a estratégia da empresa (MCCORMACK, 2001).

Conforme Rosemann, De Bruin e Hueffner (2004), diversos estudos comprovam que a orientação a processos de negócio é uma prática gerencial de implementação complexa, na qual muitas organizações encontram dificuldades em atingir estágios mais elevados de maturidade, principalmente em função dos esforços de mudança organizacional e cultural requeridos. Visando apoiar a empresa no aumento de sua capacidade de execução estratégica, definiu-se um conjunto de ações para melhoria da gestão dos processos de negócio:

a) Estabelecer senso de urgência para a mudança. Conforme Kotter (1997) as mudanças organizacionais somente são bem sucedidas quando precedidas de um amplo entendimento das razões pelas quais a mudança é necessária, capaz de mobilizar recursos e obter comprometimento;

b) Identificar processos críticos. Embora a longo prazo exista a expectativa de abranger a todos os processos, a maior parte das empresas inicia focando naque- les poucos e críticos que têm maior impacto sobre o sucesso estratégico da organização (MULLER, 2003);

c) Documentar adequadamente os processos. De acordo com McCormack e Rauseo (2005), o primeiro passo para o estabelecimento da orientação a processos de negócio é fazer com que todos na organização passem a enxergá-la através de um novo modelo mental, ou visão de processo. Além da utilização de um padrão único de notação, esta visão compartilhada de processo deve ser construída através de ampla participação, tanto nos esforços diretos para elaboração da documentação, quanto na validação dos resultados, possibilitando a identificação e superação de lacunas dos processos atuais;

d) Designar um responsável para cada processo crítico. De acordo com Hammer e Stanton (1999), a existência de "process owners" talvez seja a diferença mais visível entre uma organização tradicional e aquela orientada a processos, sendo que a indicação de executivos seniores para a função, sinaliza a importância da posição e o comprometimento da alta administração;

e) Revisão dos indicadoreschave. Garantir que os indicadores-chave dos processos críticos estejam representados no Balanced Scorecard da empresa;

f) Comunicar, comunicar e comunicar. Esforços continuados de comunicação são essenciais não apenas para fornecer feedback e garantir a mobilização das equipes, mas também para disseminar a noção de que o fo- 
Alberto Pavlick Caetani

Marinês Steffanello

co em processos é a melhor forma para garantir foco nos clientes, de modo a criar e sustentar uma cultura de gestão orientada ao mercado e resultados (PINHO, 2008).

A discussão, priorização e implementação das ações de melhoria propostas não fizeram parte do escopo do presente estudo.

\section{Considerações Finais}

Em um ambiente econômico cada vez mais instável, complexo, competitivo e globalizado, as empresas precisam enfrentar o desafio de formular e implementar estratégias que lhes garantam vantagens competitivas sustentáveis ao longo do tempo. Mesmo considerando que a formulação e implementação da estratégia empresarial sejam também impactadas pelo ambiente e fatores externos à organização, é consenso que a gestão adequada dos processos internos é fundamental para o sucesso das empresas. Avaliando o funcionamento das organizações, Bouer (2008, p. 66) destaca que "a capacidade de execução da estratégia está fortemente correlacionada ao desempenho superior nos processos-chave da organização", de modo que os processos transformam-se em ativos estratégicos das empresas. Assim para atender requisitos de integração, flexibilidade e inovação, é necessário gerenciar adequadamente os processos internos, pois, conforme diversos autores contemporâneos (HAMMER; CHAMPY, 1994; MCCORMACK; JOHNSON, 2001; HARMON, 2004) as empresas poderão melhorar significativamente seu desempenho empresarial através da adoção de práticas de gestão orientadas a processos.

Este trabalho buscou identificar oportunidades para melhoria da capacidade de execução estratégica em uma refinaria de petróleo, a partir de mudanças
Raquel Janissek-Muniz

Everton da Silveira Farias

organizacionais decorrentes da aplicação de práticas de gestão orientadas a processos. A pesquisa, realizada através de estudo de caso único, teve caráter exploratório, buscando avaliar o grau de maturidade da empresa em relação à orientação a processos, assim como identificar os obstáculos enfrentados na execução estratégica, o impacto dos fatores organizacionais sobre os indicadores estratégicos e as deficiências existentes no modelo de gestão atual, estabelecendo relações entre essas variáveis, de modo a possibilitar o entendimento de como a adoção de práticas de gestão orientadas a processos poderia ajudar a empresa a melhorar seu desempenho e aumentar sua capacidade de execução estratégica.

Os resultados apurados demonstraram que os principais obstáculos enfrentados pela empresa para executar as ações propostas em seu Planejamento Estratégico (deficiências na articulação de ações envolvendo múltiplas gerências; falta de compartilhamento de informações entre áreas; pouco feedback sobre a efetividade estratégica das ações; e falta de clareza na atribuição de responsabilidades pela tomada de decisão e implementação das ações) poderiam ser, ao menos em parte, superadas através de práticas orientadas a processos.

A análise da maturidade da empresa em relação à orientação a processos evidenciou que, apesar dos recursos aplicados no acompanhamento do Planejamento Estratégico, do sistema de gestão de qualidade certificado pelas normas ISO 9001, ISO 14001 e OHSAS 18001, e da implantação de um sistema de gestão integrado (ERP), a empresa ainda não possui uma visão de processo suficientemente ampla e disseminada por toda a organização. Segundo Armistead, Pritchard e Machin (1999), quando coexistem dentro da organização várias visões de processo, a ambigüidade resultante conduz à ausência de entendimento comum, com impactos sobre a 
Gestão orientada a processos de negócio: oportunidades para melhoria da execução estratégica em uma refinaria de petróleo

dinâmica interdepartamental e sobre a eficácia do sistema de medição de desempenho, na medida em que os indicadores estratégicos não conseguem refletir efetivamente os resultados dos processos de negócio.

Dessa forma as ações de melhoria e transformação propostas visaram, fundamentalmente, criar as condições para a construção de uma visão de processo abrangente e compartilhada, construindo o que McCormack e Rauseo (2005) designam como modelo mental que suporte o entendimento do modo de fazer negócio, requisito essencial para atingir estágios superiores na gestão orientada a processos.

A presente pesquisa apresentou algumas limitações que acabaram restringindo o entendimento mais amplo do fenômeno, do contexto e do comportamento das variáveis envolvidas, tais como a não aplicação de entrevistas em profundidade, o tipo de amostra utilizado e a falta de uma pesquisa documental mais extensiva.

Finalmente, considerando as limitações citadas, alguns temas podem ser sugeridos para trabalhos complementares:

a) Avaliação das práticas de gestão orientadas a processos a partir de diferentes modelos de maturidade;

b) Estudos de maturidade comparativos entre diferentes empresas (benchmarking);

c) Avaliação do alinhamento entre o modelo de processos da empresa e o modelo de processos aplicado pelo ERP;

d) Gestão do conhecimento como suporte à gestão orientada a processos.

\section{Referências}

ADLER, P. S. et al. Perspectives on the productivity dilemma. Journal of Operations Management, v. 27, p. 99-113, 2009.
ARMISTEAD, C.; PRITCHARD, J-P; MACHIN, S. Strategic business process management for organizational effecttiveness. Long Range Planning, v. 32, n. 1, p. 96-106, 1999.

ARMISTEAD, C.; PRITCHARD, J-P. Business process management: lessons from European business. Business Process Management Journal, v. 5, n. 1, p. 10-32, 1999.

BEER, M.; EISENSTAT, R.A. The silent killers of strategy implementation and learning. Sloan Management Review, Massachusetts, v. 41, n. 4, p. 29-40, summer 2000.

BIRKINSHAW, J.; GODDARD, J. Qual é seu modelo de gestão? HSM Management, v. 4, n.75, p. 58-66, jul. /ago. 2009.

BOUER, R. Fatores determinantes para a tradução da estratégia em ações e resultados: a disciplina da execução. São Paulo, 2008. Tese (Doutorado em Engenharia) - Escola Politécnica da Univ. de São Paulo, São Paulo, 2008.

CARNEIRO, J. Mensuração do desempenho organizacional: questões conceituais e metodológicas. In: GUTIERREZ, $M$. Estudos em negócios IV. Rio de Janeiro: MAUAD, 2005, p. 145-176.

FISHER, D. M. The business process maturity model: a practical approach for identifying opportunities for optimization. Sep. 2004. Disponível em: <http://www.bp trends.com /publicationfiles/10-04 ART BP Maturity Model-Fisher.pdf $>$. Acesso em: 04 jul. 2010.

GODET, M. The Art of scenarios and strategic Planning: tools and pitfalls. Technological Forecasting and Social Change, v. 65, p. 3-22, 2000.

GODET, M.; DURANCE, P. A prospectiva estratégica: Para as empresas e para os territórios. Ed. Dunod.; UNESCO Publishing, 2011.

HAMMER, M.; CHAMPY, J. Reenge- 
nharia: revolucionando a empresa em função dos clientes, da concorrência e das grandes mudanças da gerência. Rio de Janeiro: Campus, 1994

HAMMER, M.; STANTON, S. How process enterprises really work. Harvard Business Review, Boston, MA, v. 77, n. 6, p. 108-118, Nov./Dec. 1999.

HAMMER, M. The process audit. Harvard Business Review, Boston, MA, v. 82, n. 4, p. 111-123, Apr. 2007.

HARMON, P. Evaluating an Organization's Business Process Maturity. Business Process Trends Newsletter, v. 2, n. 3, Mar. 2004. Disponível em: <http:// www.bptrends.com/ publicationfiles/03-04 NL Eval BP Maturity - Harmon.pdf>. Acesso em: 12 set. 2010.

HARRINGTON, J. H. Aperfeiçoando processos empresariais: estratégia revolucionária para o aperfeiçoamento da qualidade, da produtividade e da competitividade. São Paulo: Makron Books, 1993.

HECKSCHER, C. The Collaborative Enterprise: managing speed and complexity in knowledge-based businesses. Yale University Press, 2007.

HREBINIAK, L. G. Obstacles to effective strategy implementation. Organizational Dynamics, vol. 35, n. 1, p. 12-31, 2006.

KAPLAN, R.S.; NORTON D.P. The balanced scorecard: translating strategy into action. Boston: Harvard Business School Press, 1996.

KAPLAN, R.S. NORTON, D.P. The strategy-focused organization: how balanced scorecard companies thrive in the new business environment. Boston, MA: Harvard Business School Press, 2001.

KOTTER, J.P. Liderando mudança. Rio de Janeiro: Campus, 1997.

MANKINS, M.C.; STEELE, R. Turning great strategy into great performance. Harvard Business Review, Boston, July/ Aug. 2005.
Raquel Janissek-Muniz

Everton da Silveira Farias

MCCORMACK, K. The development of a measure of business process orientation and its link to the interdepartamental dynamics construct of market orientation. 1999. Disponível em: <http://www.drkresearch.org/contact_us/O B_750/BPO_base_research_ _99.pdf >. Acesso em: 12 abr. 2010.

MCCORMACK, K. Benchmarking using the BPO maturity model. 2000. Disponível em: <http://www.drkresearch. org/Publications/Download/BPO_benchma rking_article.doc $>$ Acesso em: 22 jun. 2010 .

MCCORMACK, K. Business process orientation: do you have it? Quality Progress, v. 34, n. 1, p. 51-57, 2001.

MCCORMACK, K; JOHNSON, W.C. Business process orientation: gaining the e-business competitive advantage. Boca Raton: CRC Press. 2001.

MCCORMACK, K.; RAUSEO, N. Building an enterprise process view using cognitive mapping. Business Process Management Journal, v. 11, n.1, p. 63-74, 2005 .

MOTTA, Ricardo. A busca da competitividade nas empresas. In: RAE - Revista de administração de empresas, São Paulo, v. 35, n. 1, p. 12-16, mar./abr. 1995.

MÜLLER, C.J. Modelo de gestão integrando planejamento estratégico, sistemas de avaliação de desempenho e gerenciamento de processos: MEIO modelo de estratégia, indicadores e operações. Porto Alegre, 2003. Tese (Doutorado em Engenharia) - Escola de Engenharia, UFRGS, Porto Alegre, 2003.

NEELY, A. et al. Realizing strategy through measurement. International Journal of Operations \& Production Management, v. 14, n. 3, p. 140-152, 1994.

NEILSON， G.L.; MARTIN， K.L.; POWERS, E. The secrets to successful 
Gestão orientada a processos de negócio: oportunidades para melhoria da execução estratégica em uma refinaria de petróleo

strategy execution. Harvard Business Review, Boston, May/June 2008.

OSTROFF, F. The horizontal organization: what the organization of the future looks like and how it delivers value to customers. New York: Oxford University Press, 1999.

PAULK, M. C. A history of the capability maturity model for software. Software Quality Professional Magazine, v.12, n. 1, p 5-19, 2009.

PINHO, B. et al. Estruturação de escritório de processos. Relatório Técnico do Departamento de Informática Aplicada, UFRJ, n. 1, dez. 2008.

RIBEIRO, H.R. Indicadores sistêmicos compreendendo o desempenho organizacional com o uso do paradigma sistêmico: um estudo aplicado ao Balanced Scorecard de empresa da indústria do refino de petróleo. Porto Alegre, 2006. Dissertação (Mestrado Profissional em Administração) - PPGA, UFRGS, Porto Alegre, 2006.

ROSEMANN, M.; DE BRUIN, T.; HUEFFNER, T. A model for business process management maturity. ACIS Proceedings, 2004. Disponível em: <http://aisel.aisnet.org/ acis2004/6> Acesso em: 12 out. 2010.

RUMMLER, G.; BRACHE, A.P. Improving performance: how to manage the white space on the organizational chart. San Francisco: Jossey-Bass, 1995.

SANTOS, R.P.C. Engenharia de Processos: análise do referencial teóricoconceitual, instrumentos, aplicações e casos. Rio de Janeiro, 2002. Dissertação (Mestrado em Eng. de Produção) COPPE, Univ. Federal do Rio de Janeiro, 2002.

SANTOS, R.P.C. As tarefas para gestão de processos. Rio de Janeiro, 2007. Tese (Doutorado em Eng. de Produção) COPPE, Univ.Federal do Rio de Janeiro, 2007.
VRAKKING, W. J. The implementation game. Journal of Organizational Change Management, v. 8, n. 3, p. 31-46, 1995.

YIN, R.K. Estudo de caso: planejamento e métodos. São Paulo, Bookman, 2005. 